\title{
JOURNAL
}

of the

\section{AUSTRALIAN MATHEMATICAL SOCIETY}

Series A - Pure Mathematics and Statistics

\section{Volume 31 Part 3 OCTOBER 1981}

E. C. Weinberg

G. KowOL

D. W. TRENERRY

Hiroshi YamaguchI

SHINJI YAMASHITA

LEIF ARKERYD

OLAv NJÅstad

D. B. MCAlister

J. M. HowIE

Mohammad Reza A.

MOGHADDAM

BRUCE RICHMOND and

George SZeKeres

D. MEIER and

JAMES WIEgOLD

D. R. Stinson
Real order-automorphism groups . . . . . . 257

Nilpotent and semi-n-abelian groups . . . . . . 262

A class of oi -extreme Minkowski-reduced forms . . 269

Remarks on multipliers on certain function spaces on groups . . . . . . . . . . . . . . 276

Dirichlet-finite outer functions . . . . . . . . . 289

Imperfect bifurcation and Banach space singularity theory . . . . . . . . . . . . . . . 294

Regular Wallman compactifications of rim-compact spaces . . . . . . . . . . . . . . . 312

Regular Rees matrix semigroups and regular Dubreil-

Jacotin semigroups . . . . . . . . . . . 325

A congruence-free inverse semigroup associated with

a pair of infinite cardinals . . . . . . . . 337

On the Schur-Baer property . . . . . . . . . 343

Some formulas related to dilogarithms, the zeta

function and the Andrews-Gordon identities . . 362

Growth sequences of finite groups V . . . . . . 374

Some results concerning frames, Room squares, and subsquares . . . . . . . . . . . 376 


\section{PREPARATION OF TYPESCRIPTS}

1. The author should keep a complete copy of the submitted article; the Society will not accept responsibility for any loss. Two copies of the typescript should be submitted.

2. Each typescript should include: (i) an abstract of not more than 150 words, preferably containing no formulae, and certainly containing no complicated formulae and no references, (ii) a 1980 Mathematics subject classification (Amer. Math. Soc.); the classification scheme is described in Mathematical Reviews, Index to Volume 56 (1978), (iii) if the title is long, a shortened form of it, no more than forty characters in length, including spaces.

3. The article should be typed or photocopied on high quality A4 or quarto bond paper, on one side only, with at least double spacing, and with a generous margin (at least $3 \mathrm{~cm}$ ) all around.

4. The conventions of $A$ mamual for authors of mathematical papers published by the American Mathematical Society should be observed. Two alternative styles for references and quotations are described below. Authors are requested to use one and only one style consistently throughout their typescript.

STYLE 1. A typical reference in the list of references would be:

T. M. Cherry (1965), 'Infinite linear systems with homogeneous kernel of degree -1 ', J. Austral. Math. Soc. 5, 129-168.

A corresponding reference in the text would be: Cherry (1965), p. 155.

STYLE 2. A typical reference in the list of references would be:

[3] L. Grüschen, 'Pseudo-quasi-ergodic theorems', J. Austral. Math. Soc. 4 (1960), 2-3.

A corresponding reference in the text would be: Grüschen [3], or [3], [4], [9], or Grüschen (22, 3]).

In either style, the list of references should be in alphabetical order of surnames of first authors.

5. Explain clearly what symbols are to be set in special typefaces (such as cursive, fraktur, script, bold) and what is required with any unusual symbols (which should wherever possible be chosen from symbols available to the printer). This is best done by supplying a separate page entitled "Notes to the Compositor" in which conventions and requirements are fully set out, and by drawing attention to particular symbols at their first appearance in the typescript. The Notes to the Compositor should include a list of all symbols and foreign letters used in the article. Be careful to distinguish between similar symbols, such as $v, \nu, V, k, \kappa, K, 1,1,1, e, \phi$ (phi), $\varnothing$ (empty set), $\varepsilon$ (epsilon), $\in$ (membership), and so on. Normally 0 will be set as zero; if $O$ or $O$ is required, then show this. Distinguish between inequalities $\langle$,$\rangle and angular brackets \langle$,$\rangle .$

Correspondence concerning the printing of papers after their acceptance for publication should be addressed to G. Virsik.

Journal of the Australian Mathematical Society, Series A-Pure Mathematics and Statistics, is published bimonthly by the Australian Mathematical Society, Department of Mathematics, University of Queensland, St. Lucia, Qld. 4067, Australia. Second class postage is paid at Ann Arbor, Michigan 48106. Postmaster: Send address change notices to Dr V. G. Hart, Journal of the Australian Mathematical Society, Department of Mathematics, University of Queensland, St. Lucia, Qld. 4067, Australia. 